\title{
Quality of life in postmenopausal women with reduced bone mineral density: psychometric evaluation of the Polish version of QUALEFFO-41
}

\author{
Grażyna Bączyk1, Tomasz Opala², Paweł Kleka
}

1Department of Nursing Faculty of Health Sciences Poznan University of Medical Sciences, Poland

2Department of Mother and Child Health, Poznan University of Medical Sciences, Poland ${ }^{3}$ Institute of Psychology, Adam Mickiewicz University Poznan, Poland

Submitted: 6 July 2010

Accepted: 20 October $2010 z$

Arch Med Sci 2011; 7, 3: 476-485

DOI: 10.5114/aoms.2011.23415

Copyright ( 2011 Termedia \& Banach

\section{Abstract}

Introduction: Evaluation of the quality of life of patients with osteoporosis concerns the physical, emotional, social and pain quality of life domains. The aim of the research was to describe the psychometric properties of the Polish version of QUALEFFO-41 in 253 Polish postmenopausal women with osteopenia or osteoporosis and in 132 postmenopausal women with normal BMD.

Material and methods: The internal reliability of QUALEFFO-41 was studied using Cronbach's alpha coefficient. The reproducibility of the QUALEFFO-41 scales was assessed using Pearson's correlation. The capacity of questions to discriminate between women with reduced bone mineral density (BMD) and normal subjects was assessed by conditional logistic regression to derive an odds ratio with $95 \%$ confidence intervals. The discriminative power, which measures the ability of the questionnaire to discriminate between patients, was assessed by clinical validity. Additionally, receiver operating characteristic (ROC) curves were constructed to assess the ability of QUALEFFO-41.

Results: Cronbach's $\alpha$ coefficient reflecting the reliability and repeatability of the instrument for all domains was satisfactory. Results of scores for domains of QUALEFFO-41 and the score for total QUALEFFO-41 demonstrate a significant difference $(p<0.001)$ among all groups; only in the case of the pain domain was there a significant difference at the level of $p<0.01$ between normal subjects and osteoporotic patients. Receiver operating characteristic curve analysis demonstrated a good discriminating capacity of individual domains and total QUALEFFO-41 score.

Conclusions: The Polish version of QUALEFFO-41 can be used among patients with reduced BMD compared to normal subjects, independently of vertebral fractures, as it is coherent and discriminates well between women with reduced BMD and normal subjects.

Key words: QUALEFFO-41, quality of life, vertebral fracture, psychometric properties, postmenopausal women.

\section{Introduction}

A consequence of reduced bone mineral density (BMD) is osteoporosis, which constitutes a problem not only for patients with osteoporosis but also for their families and society as a whole [1-3].

\author{
Corresponding author: \\ Grażyna Bączyk MA, PhD \\ Department of Nursing \\ Faculty \\ of Health Sciences \\ Poznan University \\ of Medical Sciences \\ 11 Smoluchowskiego \\ 60-179 Poznan \\ Phone: +48616559261 \\ Fax: +48 616559266 \\ Poland \\ E-mail: gbaczyk@ump.edu.pl
}


The principal goals of health care for postmenopausal women with reduced BMD are: to prevent fractures, to minimize functional loss, maintain independence, and preserve quality of life (QoL). In the past two decades, health status instruments for assessment of quality of life have proven to be valuable, relevant outcome measures in both clinical trials and clinical practice [4]. Questionnaires based on health status variables, such as mobility, mood, and social function, are particularly relevant because they assess the aspects of outcome that most concern the individual patient [5]. Generic health status instruments can be used to compare patients with different diseases. Several generic instruments for measuring QoL have been developed, for example the Nottingham Health Profile (NHP) [6], the Sickness Impact Profile (SIP) [7], the Short Form 36 of the Medical Outcomes Study (SF-36) [8], the EuroQoL (EQ-5D) [9], or the World Health Organization Quality of Life 100 and BREF (WHOQOL 100 and BREF) [10].

Since important areas for specific patient groups may be omitted, disease-specific instruments have also appeared for patients with osteoporosis [1117]. Among them, there is the Quality of Life Questionnaire of the European Foundation for Osteoporosis (QUALEFFO 41) [18]. The 41 questions are grouped in the following five domains: pain, physical function (activities of daily living, jobs around the house and mobility), social function, general health perception and mental function. The QUALEFFO-41 questionnaire has been translated from English into many languages, including into Polish.

We chose QUALEFFO-41 for our study because this questionnaire has been the most widely used in European studies.

The QUALEFFO-41 scale is used generally for osteoporosis patients with vertebral fractures. However, in clinical trials it can be found that this scale is also used in osteoporosis patients without vertebral fractures, especially when BMD measurements were made in the lumbar spine. We were interested whether the Polish version of QUALEFFO-41 is able to distinguish patients with reduced BMD from normal subjects, independently of vertebral fractures.

Therefore our study aimed to describe the psychometric properties of the Polish version of QUALEFFO-41 in relation to score construction, reliability, and validity among postmenopausal women with reduced BMD, independently of vertebral fractures.

In addition, the study was to assess the quality of life among postmenopausal women with reduced $B M D$ and compare the quality of life among women with and without vertebral deformities.

\section{Material and methods}

\section{Material}

Two hundred and fifty-three Polish postmenopausal women with osteopenia or osteoporosis independently of vertebral fractures and 132 postmenopausal women with normal BMD were included in this study, all patients living in Poznan. The research was carried out from August 2007 to July 2008. We obtained written consent of the patient to carry out these examinations. The inclusion criteria were those aged 50-66 years who were recruited from outpatients in the Menopause and Osteoporosis Outpatient in Poznan and who had reduced BMD compared to normal subjects, independently of vertebral fractures. According to the World Health Organization (WHO) [19] definition, subjects were classified as having osteoporosis if they had a T-score $<-2.5 \mathrm{SD}$, osteopenia if $-2.5<\mathrm{T}$-score $<-1.0 \mathrm{SD}$, and normal BMD if T-score was $>-1.0$ SD in at least one of the measured areas (either the lumbar spine, or femoral, or both). In our study BMD measured in the lumbar spine (T-score) was the basis for the group classification. Subjects with secondary osteoporosis, metabolic bone disease, malignant bone metastasis, endocrine, gastrointestinal, rheumatological or haematological disorders, hypogonadal states, osteogenesis imperfect, glucocorticoid treatment or different coexisting illness, whose presence could influence the assessment of QoL, were excluded from the study. The control group included postmenopausal women with normal BMD aged 50-66 years. They were also recruited from the Menopause and Osteoporosis Outpatient in Poznan, during consultation in this outpatient. For the control group exclusion criteria were the same as those used for women with osteopenia and osteoporosis.

\section{Ethics}

The study was approved by the Regional Research Ethical Committee of the University of Medicine in Poznan.

\section{Data collection and measurements}

All patients were interviewed for data collection on clinical and sociodemographic parameters: age at menopause, marital status, school education, job and workplace, previous non-vertebral fractures, use of bisphosphonates, use of hormone therapy, history of osteoporosis, smoking and drinking alcohol.

\section{Anthropometric data}

Weight and height were measured at the time of bone densitometry measurements. The 
body mass index (BMI) was calculated as body weight/height ${ }^{2}\left(\mathrm{~kg} / \mathrm{m}^{2}\right)$.

\section{Bone mineral density measurements}

Bone mineral density of the lumbar spine (L1L4) in the anterior-posterior projection was measured in women by dual energy X-ray absorptiometry (DXA). Bone mineral density was assessed in the lumbar spine using a LUNAR device.

\section{Vertebral morphometry}

Among patients with osteopenia and osteoporosis we assessed vertebral fractures from L1-L4 using the DXA method of vertebral fracture assessment (VFA) according to the Genant criteria. Vertebral deformity was defined when anterior, middle, or posterior height loss was more than $20 \%$. Mild fractures were defined as $20-25 \%$ height loss, and moderate fractures as more than $25 \%$ height loss [20]. Vertebral fractures were assessed using a Luna Prodigy Advance device.

\section{Questionnaires}

The European Foundation for Osteoporosis QUALEFFO questionnaire was previously adapted and translated from the original version into the Polish version [18]. Therefore we did not adapt and translate this questionnaire. We have permission for using QUALEFFO-41 from The European Foundation for Osteoporosis. The Polish version of QUALEFFO was administered to all subjects. The Polish version of QUALEFFO, like the original version, consists of 41 questions divided into five domains: pain, physical function, social function, general health perception and mental function. In our study the physical function domain was divided into: activities of daily living (ADL), jobs around the house and mobility. Individual domain scores and total score can be evaluated. Domain scores were calculated by summing the answer scores and submitting the sum to a linear transformation to a 100 scale, where 0 represents the best and 100 the worst QoL [18].

Additionally we used a second questionnaire, WHOQOL-100. The Polish WHOQOL group adapted and translated the WHOQOL-100 questionnaire from the original version into the Polish version [10]. We have permission for using WHOQOL-100 from the Polish WHOQOL group. WHOQOL-100 contains the following domains: pain and discomfort, activities of daily living, environment, mobility, social function, general health perception and mental function. Lower scores indicate better QoL [10]. After a short interview, a specialist led the women to the next research. The subjects completed the questionnaire alone in a separate room. We checked whether all questions had been answered.

\section{Statistical analysis}

The answers to each question in QUALEFFO-41 were scored from 1 to 5 , except for social function; questions 23, 25 were scored from 1 to 3 and questions 24, 26, 27, 28 were scored from 1 to 4. For questions 24, 29 the answer "not applicable" and question 26 the answer "no cinema or theatre within a reasonable distance" were not scored. The scores of questions 33, 34, 35, 37, 39, 40 were reversed so that a low score indicates better health and a high score indicates worse health. Individual domain scores and total score can be evaluated. Domain scores were calculated by summing the answer scores and submitting the sum to a linear transformation to a 100 scale. The total score was computed by summing the scores of all questions and submitting the sum to a linear transformation to a 100 scale; 0 represents the best and 100 the worst QoL [18]. Descriptive statistics of all variables are presented as the percentage, mean and SD. Comparisons between groups were assessed by one-way analysis of variance (ANOVA) with post hoc tests for parametric values or by Kruskal-Wallis test and $\chi^{2}$ test for nonparametric values.

The validity of the specific questionnaire was studied: the score construction used multitrait analyses: "floor effect" and "ceiling effect", convergent validity, discriminant validity.

Convergent validity indicates the percentage of question scores correlating with the domain score better than 0.40 . Discriminant validity indicates the percentage of question scores correlating better with their own domain score than with the scores of other domains.

The internal reliability of QUALEFFO-41 was studied using Cronbach's $\alpha$ coefficient. Minimum values of greater than or equal to 0.70 have been recommended for group [21]. In addition, the reproducibility of the QUALEFFO-41 scales was assessed using Pearson's correlation coefficient among the same patients, who returned for a follow-up visit after 4 weeks. The capacity of questions to discriminate between women with reduced BMD and normal subjects was assessed by conditional logistic regression to derive an odds ratio with $95 \%$ confidence intervals. The concurrent validity, which is a measure of correlation between similar domains, was assessed by correlation of QUALEFFO-41 scores and WHOQOL-100 scores regarded as standard. The discriminative power, which measures the ability of the questionnaire to discriminate between patients with reduced BMD and patients with or without vertebral deformities, was assessed by clinical validity.

Additionally, receiver operating characteristic (ROC) curves were constructed to assess the ability 
of the QUALEFFO-41 individual score domain and total score to discriminate between patients with osteopenia and osteoporosis from subjects with normal BMD. The limit of significance was set at $p<0.05$ for all analyses. All statistical analyses were carried out using SPSS for Windows version 14.

\section{Results}

\section{Sociodemographic and clinical results}

The total study sample consisted of 385 individuals. Table I shows demographic, clinical and densitometric data of patients grouped according to the WHO definition [19]. A significant difference $(p<0.001)$ was found among the three groups for age, BMI, previous non-vertebral fractures, paid work, T-score and BMD. No statistically significant differences were observed between the groups for age at menopause, level of education, marital situation, use of hormone therapy and smoking. Table II shows risk factors in subjects.

Among patients with osteopenia and osteoporosis we assessed vertebral fractures from L-1-L-4 using the DXA method of vertebral fracture assessment (VFA) according to the Genant criteria [20]. Only $8.9 \%$ of patients with osteopenia and $21.2 \%$ of patients with osteoporosis had mild vertebral deformities and 3 women had moderate vertebral deformities.

\section{Evaluation of psychometric properties}

\section{Score construction}

Table III shows the results of the multitrait analysis of the QUALEFFO scale grouped according to the domains: pain, physical function (activities of daily living, jobs, mobility), social function, general health perception, and mental function. The "floor

Table I. Sociodemographic and clinical characteristics of women according to group $(n=385)$

\begin{tabular}{|c|c|c|c|c|}
\hline Parameters, number & $\begin{array}{l}\text { Normal subjects } \\
(\text { T-score > -1.0) } 132\end{array}$ & $\begin{array}{c}\text { Osteopenic patients } \\
(-2.5<\text { T-score } \leq-1.0) 168\end{array}$ & $\begin{array}{l}\text { Osteoporotic patients } \\
\text { (T-score } \leq-2.5) 85\end{array}$ & Value of $p$ \\
\hline Age (mean years, SD) [years] & $55.5(5.1)$ & $57.8(4.8)$ & $59.9(5.2)$ & $<0.001$ \\
\hline $\begin{array}{l}\text { Body mass index (BMI) } \\
{\left[\mathrm{kg} / \mathrm{m}^{2}\right] \text { (mean, SD) }}\end{array}$ & $26.0(3.9)$ & $24.7(4.1)$ & $22.3(3.1)$ & $<0.001$ \\
\hline $\begin{array}{l}\text { Age at menopause } \\
\text { (mean years, SD) }\end{array}$ & $49.2(3.5)$ & $48.5(5.2)$ & $49.7(4.5)$ & 0.134 \\
\hline Education (\%) & & & & $0.120^{b}$ \\
\hline Basic & 1.5 & 4.8 & 2.4 & \\
\hline Work-related & 12.9 & 10.1 & 11.8 & \\
\hline Higher & 62.1 & 46.4 & 57.6 & \\
\hline Academic & 23.5 & 38.7 & 28.2 & \\
\hline \multicolumn{5}{|l|}{ Marital situation (\%) } \\
\hline Married & 59.1 & 62.5 & 62.5 & $0.861^{a}$ \\
\hline Widowed & 14.4 & 13.1 & 15.3 & $0.931^{a}$ \\
\hline Single & 12.1 & 8.9 & 8.2 & $0.639^{a}$ \\
\hline Separated/divorced & 14.4 & 15.5 & 11.8 & $0.751^{a}$ \\
\hline Paid work (\%) & 56.9 & 32.7 & 18.8 & $<0.001^{a}$ \\
\hline T-score L1-L4 (mean, SD) & $-0.16(0.80)$ & $-1.90(0.53)$ & $-3.11(0.65)$ & $<0.001$ \\
\hline BMD L1-L4 [g/cm²] & $1.10(0.11)$ & $0.91(0.13)$ & $0.8(0.08)$ & $<0.001$ \\
\hline Hormone therapy & 34.8 & 47.0 & 40.0 & $0.350^{a}$ \\
\hline Bisphosphonates & - & 22.6 & 70.6 & - \\
\hline $\begin{array}{l}\text { Mild vertebral deformities } \\
\text { by morphometry (\%) }\end{array}$ & 0 & 8.9 & 21.2 & - \\
\hline Drinking alcohol (\%) & 0 & 0 & 0 & \\
\hline \multicolumn{5}{|l|}{ Smoking (\%) } \\
\hline Never & 53 & 42.9 & 64.6 & $0.821^{a}$ \\
\hline Past & 34.2 & 44.6 & 21.2 & $0.636^{a}$ \\
\hline Current & 13.0 & 13.0 & 14.0 & $0.944^{a}$ \\
\hline
\end{tabular}

$p$-value by one-way ANOVA, aby $\chi^{2}$ test, ${ }^{b}$ by Kruskal-Wallis test 
Table II. Risk factors in postmenopausal women with reduced bone mineral density and normal subjects

\begin{tabular}{|c|c|c|c|c|c|c|c|}
\hline \multirow[t]{2}{*}{ Risk factor } & \multicolumn{2}{|c|}{$\begin{array}{l}\text { Normal subjects } \\
\text { (T-score }>-1.0)\end{array}$} & \multicolumn{2}{|c|}{$\begin{array}{l}\text { Osteopenic patients } \\
(-2.5<\text { T-score } \leq-1.0)\end{array}$} & \multicolumn{2}{|c|}{$\begin{array}{l}\text { Osteoporotic patients } \\
\quad(T \text {-score } \leq-2.5)\end{array}$} & \multirow[t]{2}{*}{ Value of $p$} \\
\hline & $N$ & $\%$ & $N$ & $\%$ & $N$ & $\%$ & \\
\hline Previous fragility fracture & 35 & 27 & 46 & 27 & 18 & 21 & 0.527 \\
\hline Parental history of fracture & 26 & 20 & 69 & 40 & 32 & 38 & 0.004 \\
\hline Current tobacco smoking & 17 & 13 & 21 & 13 & 12 & 14 & 0.972 \\
\hline $\mathrm{BMI}<19 \mathrm{~kg} / \mathrm{m}^{2}$ & 0 & 0 & 1 & 1 & 10 & 12 & $<0.01$ \\
\hline
\end{tabular}

Table III. Score construction - results of the multitrait analysis of QUALEFFO-41 scale

\begin{tabular}{|c|c|c|c|c|}
\hline Domain & $\begin{array}{l}\text { Floor } \\
\text { effect [\%] }\end{array}$ & $\begin{array}{l}\text { Ceiling } \\
\text { effect [\%] }\end{array}$ & $\begin{array}{l}\text { Convergent } \\
\text { validity [\%] }\end{array}$ & $\begin{array}{l}\text { Discriminant } \\
\text { validity [\%] }\end{array}$ \\
\hline Pain: back pain, sleep disturbance & 22.8 & 0.8 & 100 & 100 \\
\hline ADL: dressing, bathing, toilet & 15.8 & 0 & 75 & 100 \\
\hline $\begin{array}{l}\text { Jobs around the house: cleaning, cooking, washing, } \\
\text { dishes, shopping }\end{array}$ & 20.5 & 0 & 100 & 100 \\
\hline $\begin{array}{l}\text { Mobility: standing up, bending, kneeling, stairs, } \\
\text { walking, body image }\end{array}$ & 13.2 & 0 & 100 & 100 \\
\hline Social function: sport, gardening, hobby, friends & 2.8 & 0.3 & 100 & 72 \\
\hline General health perception & 1.6 & 3.4 & 100 & 100 \\
\hline $\begin{array}{l}\text { Mental function: fatigue, depression, loneliness, } \\
\text { energy, cheerfulness, hope, fear }\end{array}$ & 0 & 0 & 89 & 100 \\
\hline
\end{tabular}

effect" indicates the percentage of subjects with the lowest possible domain score (for pain it was $22.8 \%$ of subjects, for jobs around the house $20.5 \%)$. The "ceiling effect" indicates the percentage of subjects with the highest possible domain score (for general health perception it was 3.4\%, for pain $0.08 \%$ and for social function $0.03 \%$ ).

Convergent validity indicates the percentage of question scores correlating with the domain score better than 0.40 . Only for ADL and mental function were there not $100 \%$ of questions correlating with the domain score better than 0.40 .

Discriminant validity is the percentage of question scores correlating better with their own domain score than with the scores of other domains. Only for social function were there not $100 \%$ of question scores correlating better with their own domain score than the scores of other domains.

\section{Reliability}

Table IV shows the QUALEFFO-41 results summary of response rates, internal consistency, prevalence of the lowest answer category and discrimination ability of the QUALEFFO-41 questions. The response rate shows the number of valid responses for each question presented as the median and range. The response rate for all questions in all the domains of QUALEFFO-41 was high. The internal consistency of the domains, assessed by Cronbach's $\alpha$, was for the following domains: pain 0.89 , jobs around the house 0.88 , mobility 0.88 , social function 0.73 , general health perception 0.79, mental function 0.79; and for ADL was lower than for other domains: 0.66 .

The results of this study indicate a good repeatability after 4 weeks of all domains of QUALEFFO-41. Reproducibility ranged from 0.85 (ADL) to 0.94 (Pain). Total QUALEFFO reproducibility was 0.96 .

The prevalence of the lowest answer category is presented for osteopenic, osteoporosis and control subjects according to the WHO definition. The odds ratio represents the discrimination between osteopenic, osteoporotic and control subjects.

\section{Validity}

\section{Clinical validity}

Table $V$ shows the mean (SD) for three densitometry categories according to the WHO definition in the seven domains of QUALEFFO-41. A significant difference was found for all domains at $p<0.001$; only for pain was the significant difference at the level $p<0.01$ between normal subjects and osteoporotic patients and for social function between normal subjects, osteopenic patients and osteoporotic patients (Table V). 
Table IV. Evaluation of 41 questions for QUALEFFO scale in the seven domains

\begin{tabular}{|c|c|c|c|c|c|c|c|}
\hline \multirow{2}{*}{$\begin{array}{l}\text { Domain } \\
\text { (no. of } \\
\text { questions) }\end{array}$} & \multirow{2}{*}{$\begin{array}{c}\text { Response } \\
\text { rate [\%] } \\
\text { Median } \\
\text { (range) }\end{array}$} & \multirow{2}{*}{$\begin{array}{l}\text { Internal } \\
\text { consistency } \\
\text { Cronbach's }\end{array}$} & \multirow{2}{*}{$\begin{array}{l}\text { Test-retest } \\
\text { Pearson's }\end{array}$} & \multicolumn{3}{|c|}{ Prevalence of lowest answer category } & \multirow{2}{*}{$\begin{array}{c}\text { Discrimination } \\
\text { odds ratio } \\
\text { Median } \\
\text { (range) }\end{array}$} \\
\hline & & & & $\begin{array}{l}\text { Normal } \\
\text { subjects [\%] } \\
\text { Median } \\
\text { (range) }\end{array}$ & $\begin{array}{c}\text { Osteopenic } \\
\text { patients [\%] } \\
\text { Median } \\
\text { (range) }\end{array}$ & $\begin{array}{c}\text { Osteoporotic } \\
\text { patients [\%] } \\
\text { Median } \\
\text { (range) }\end{array}$ & \\
\hline Pain (5) & $\begin{array}{c}100 \\
(80-100)\end{array}$ & 0.89 & $0.94^{* *}$ & $34(32-55)$ & $21(20-60)$ & $26(25-44)$ & $1.0(0.3-1.4)$ \\
\hline ADL (4) & $\begin{array}{c}100 \\
(0-100)\end{array}$ & 0.66 & $0.85^{\star *}$ & $77(24-95)$ & $71(18-93)$ & $60(5-93)$ & $1.1(0.1-2.0)$ \\
\hline $\begin{array}{l}\text { Jobs around } \\
\text { the house (5) }\end{array}$ & $\begin{array}{c}100 \\
(71-100)\end{array}$ & 0.88 & $0.91^{* *}$ & $65(37-85)$ & $45(17-67)$ & $40(14-64)$ & $1.1(0.1-2.1)$ \\
\hline Mobility (8) & $100^{a}$ & 0.88 & $0.89^{* \star}$ & $66(42-91)$ & $53(27-79)$ & $51(15-67)$ & $1.1(0.0-4.9)$ \\
\hline $\begin{array}{l}\text { Social } \\
\text { function (7) }\end{array}$ & $100^{a}$ & 0.73 & $0.87^{\star *}$ & $42(14-84)$ & $24(14-83)$ & $24(9-81)$ & $1.0(0.1-1.5)$ \\
\hline $\begin{array}{l}\text { General } \\
\text { health } \\
\text { perception (3) }\end{array}$ & $100^{a}$ & 0.79 & $0.88^{\star \star}$ & $3(2-9)$ & $3(3-5)$ & $6(6-8)$ & $1.2(0.0-1.7)$ \\
\hline $\begin{array}{l}\text { Mental } \\
\text { function (9) }\end{array}$ & $100^{a}$ & 0.79 & $0.92^{\star *}$ & $27(2-57)$ & $14(4-35)$ & $13(0-47)$ & $1.1(0.0-1.6)$ \\
\hline
\end{tabular}

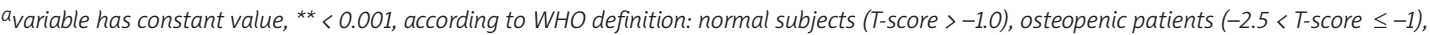
osteoporotic patients (T-score $\leq 2.5)$

Table V. Scores for QUALEFFO-41 domains and total QUALEFFO score in patients grouped according to WHO definition. The scores were transformed to a 0-100 scale

\begin{tabular}{|lcccc|}
\hline $\begin{array}{l}\text { Domain of QUALEFFO } \\
\text { (number of items) }\end{array}$ & $\begin{array}{c}\text { Normal subjects (1) } \\
(\text { T-score }>-1.0) \\
\text { Mean (SD) }\end{array}$ & $\begin{array}{c}\text { Osteopenic patients (2) } \\
(-2.5<\text { T-score } \leq-1) \\
\text { Mean (SD) }\end{array}$ & $\begin{array}{c}\text { Osteoporotic patients (3) } \\
\text { (T-score } \leq 2.5) \\
\text { Mean (SD) }\end{array}$ & Value of $p$ \\
\hline Pain (5) & $30.2(25.9)$ & $34.9(25.6)$ & $42.1(30.0)$ & $<0.01(1: 3)^{\star}$ \\
\hline ADL (4) & $11.6(12.2)$ & $16.2(14.5)$ & $19.2(12.5)$ & $<0.001(1: 2.3)^{*}$ \\
\hline Jobs around the house (5) & $13.9(15.6)$ & $24.6(21.8)$ & $27.7(20.1)$ & $<0.001(1: 2.3)^{*}$ \\
\hline Mobility (8) & $13.4(13.9)$ & $23.0(18.2)$ & $23.4(15.3)$ & $<0.001(1: 2.3)^{*}$ \\
\hline Social function (7) & $37.5(18.2)$ & $44.6(21.2)$ & $46.4(22.3)$ & $<0.01(1: 2.3)^{\star *}$ \\
\hline General health perception (3) & $46.0(19.6)$ & $55.4(20.6)$ & $60.9(24.3)$ & $<0.001(1: 2.3)^{*}$ \\
\hline Mental function (9) & $32.0(15.2)$ & $39.1(15.8)$ & $41.1(13.8)$ & $<0.001(1: 2.3)^{\star *}$ \\
\hline Total QUALEFFO score & $20.5(10.3)$ & $26.7(12.2)$ & $28.9(11.8)$ & $<0.001(1: 2.3)^{*}$ \\
\hline
\end{tabular}

Post hoc tests: *Dunnett T3, **Bonferroni

In Table $\mathrm{VI}$ results are reported which were obtained for each domain and the total QUALEFFO score by comparing osteopenic and osteoporotic patients with or without vertebral deformities assessed by morphometry. Among osteopenic patients 15 were found with mild vertebral deformities and among osteoporotic patients 15 with mild vertebral deformities and 3 with moderate vertebral deformities. A significant difference was found between patients with and without vertebral deformities for social function and total score. Among osteopenic patients a significant difference was also found for mental function and general health perception $(p<0.001)$. A significant difference was found between osteoporotic patients with and without vertebral deformities for pain and ADL (Table VI).

\section{Concurrent validity}

Table VII shows the correlation coefficient between scores of the QUALEFFO-41 and WHOQOL-100 scales. The correlation was negative among all domains excluding pain. QUALEFFO-41 scores increase with worse functioning and quality of life, while WHOQOL-100 scale scores increase with improved functioning and quality of life. There was a significant correlation among all the domains of QUALEFFO-41 and the corresponding WHOQOL-100 scales $(p<0.001)$. 
Table VI. Scores for QUALEFFO-41 domains and total QUALEFFO score in osteopenic and osteoporotic patients grouped according to the presence of vertebral deformities assessed by morphometry. The scores were transformed to a 0-100 scale and are presented as mean (SD)

\begin{tabular}{|lcccccc|}
\hline Domain of QUALEFFO & \multicolumn{3}{c}{$\begin{array}{c}\text { Osteopenic patients } \\
\text { Vertebral fractures }\end{array}$} & \multicolumn{3}{c|}{$\begin{array}{c}\text { Osteoporotic patients } \\
\text { Vertebral fractures }\end{array}$} \\
\cline { 2 - 7 } & No $(n=153)$ & Yes $(n=15)$ & $p$ & No $(n=67)$ & Yes $(n=18)$ & $p$ \\
\hline Pain & $33.4(23.2)$ & $35.5(26.5)$ & 0.628 & $38.8(29.7)$ & $54.4(28.3)$ & 0.044 \\
\hline ADL & $15.0(14.7)$ & $19.3(13.6)$ & 0.089 & $17.4(11.7)$ & $25.7(13.7)$ & 0.012 \\
\hline Jobs around the house & $22.4(22.4)$ & $30.7(18.9)$ & 0.028 & $27.0(20.2)$ & $30.3(20.3)$ & 0.545 \\
\hline Mobility & $22.1(18.6)$ & $25.3(16.9)$ & 0.311 & $22.5(13.4)$ & $26.7(21)$ & 0.427 \\
\hline Social function & $42.5(20.5)$ & $50.3(22.1)$ & 0.033 & $46.1(22.5)$ & $49.9(25.8)$ & 0.029 \\
\hline General health perception & $52.0(14.5)$ & $64.3(16.7)$ & $<0.001$ & $60.2(23.4)$ & $63.4(28.2)$ & 0.62 \\
\hline Mental function & $36.4(14.5)$ & $46.0(17.2)$ & $<0.001$ & $40.3(14)$ & $44.0(12.7)$ & 0.323 \\
\hline Total QUALEFFO score & $25.4(12.3)$ & $30.3(11.3)$ & 0.02 & $28.0(11.1)$ & $34.3(14.9)$ & 0.022 \\
\hline
\end{tabular}

Higher scores indicate poorer QoL

Table VII. Correlation coefficient between scores of QUALEFFO-41 and WHOQOL-100 scales

\begin{tabular}{|c|c|c|c|}
\hline Domain of QUALEFFOa & Domain of WHO-100b & Correlation coefficient & Value of $p$ \\
\hline Pain & Pain & 0.609 & $<0.001$ \\
\hline Activities of daily living & Activities of daily living & -0.604 & $<0.001$ \\
\hline Jobs around the house & Environment & -0.25 & $<0.001$ \\
\hline Mobility & Mobility & -0.664 & $<0.001$ \\
\hline Social function & Social function & -0.279 & $<0.001$ \\
\hline General health perception & General health & -0.493 & $<0.001$ \\
\hline Mental function & Mental function & -0.463 & $<0.001$ \\
\hline
\end{tabular}

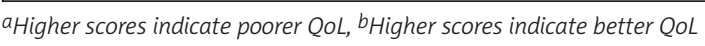

\section{Predictive validity}

Table VIII shows that the calculated values are under the curve for each domain and total score. All values were between 0.58 and 0.68 , which implies a medium discrimination capacity.

Table VIII. Receiver operating characteristic (ROC) curve analysis for QUALEFFO-41 domains and total OUALEFFO score

\begin{tabular}{|lc|}
\hline Domain of QUALEFFO-41 & QUALEFFO-41 Area (SE) \\
\hline Pain & $0.58(0.03)$ \\
\hline Activities of daily living & $0.64(0.03)$ \\
\hline Jobs around the house & $0.68(0.03)$ \\
\hline Mobility & $0.68(0.03)$ \\
\hline Social function & $0.61(0.03)$ \\
\hline General health perception & $0.66(0.03)$ \\
\hline Mental function & $0.64(0.03)$ \\
\hline Total QUALEFFO-41 score & $0.67(0.03)$ \\
\hline
\end{tabular}

Area under the curve $=0.5$, higher values indicate better discrimination, higher values indicate better discrimination

\section{Discussion}

In 1992 the European Foundation for Osteoporosis formed a working party to develop a specific quality of life questionnaire (QUALEFFO) for patients with vertebral fractures [18]. The first version of QUALEFFO included 48 questions and six visual analogue scales. Most questions were new, but two were taken from the Mediterranean Osteoporosis Study (MEDOS) Questionnaire [22], and the European Vertebral Osteoporosis Study (EVOS) [23], questionnaires. During evaluation of psychometric properties of QUALEFFO, seven were removed from further analysis because there was a low response rate (less than 50\%) to these questions. The 41 questions were grouped in the following five domains: pain, physical function (activities of daily living, jobs around the house and mobility), social function, general health perception and mental function.

The original QUALEFFO questionnaire is considered as a common and widely used version of the questionnaire in order to evaluate the quality 
of life in osteoporotic patients with vertebral fractures. The results of evaluation of psychometric properties of the original version of QUALEFFO are adequate. The internal coherence within the various domains is adequate without excessive redundancy, as indicated by the analyses of Cronbach's $\alpha$. QUALEFFO can discriminate between patients with vertebral fractures and age- and sex-matched control subjects, indicating worse QoL in patients than in controls. In international clinical trials QUALEFFO-41 was used to assess changes during treatment in patients with vertebral fractures. In the Multiple Outcomes of Raloxifene Evaluation (MORE) study [24], QUALEFFO-41 was shown to be able to discriminate satisfactorily between patients with or without prevalent vertebral fractures. In osteoporosis low BMD is asymptomatic and patients with or without low-grade fractures may be unaware of their condition. Patients with reduced BMD could have decreased QoL; contributing to it is their fear of falling or of future fractures [25-6].

In the present study QUALEFFO-41 was administered to patients with reduced BMD, independently of vertebral fractures. The aim of the research was to describe the psychometric properties of the Polish version of QUALEFFO-41 among postmenopausal women with reduced BMD compared to normal subjects, independently of vertebral fractures.

The aim of this study was also to answer whether the Polish version of QUALEFFO-41 is able to distinguish postmenopausal women with reduced BMD from normal subjects, independently of vertebral fractures. In addition, the study was to assess the quality of life among postmenopausal women with reduced BMD and compare the quality of life among women with and without vertebral deformities.

We classified our samples into three densitometry categories, according to the WHO, as shown in Table I. The results of the score construction of the multi-trait analysis (Table III) show floor and ceiling effects, indicating the percentage of subjects with the lowest or highest possible scores. The convergent and discriminant validity concern the homogeneity of questions in one domain. The convergent validity indicates the percentage of question scores correlating better than 0.40 with the domain score. The discriminant validity indicates the percentage of question scores correlating better with their domain score than with the scores of other domains.

The results of the multitrait analysis indicate the similarity between the score construction of the Polish QUALEFFO-41 and the score results of the original version. In our study reports the scores of individual questions are better correlated with their own domain than with other domains, reflecting good discriminant validity. These findings are similar to the original QUALEFFO [18].

Cronbach's $\alpha$ coefficient reflecting the reliability of the instrument for all domains was satisfactory. For three domains, reliability coefficients were higher than 0.80 and for three domains were higher than 0.70 . The activities of daily living exhibited a lower value of 0.66 . The results of this study indicate good repeatability after 4 weeks of all domains of QUALEFFO-41. These results (good internal consistency and test-retest reliability) show a similar tendency to the findings of the original and another study $[18,28]$.

Results scores for domains of QUALEFFO-41 and the score for total QUALEFFO-41 demonstrate a significant difference $(p<0.001)$ among all groups; only in the case of the pain domain was there a significant difference at the level of $p<0.01$ between normal subjects and osteoporotic patients, and in the case of the social function domain a difference was noted between normal subjects, osteopenic patients and osteoporotic patients. The results of this study also show a significant impairment of QoL in patients with reduced BMD compared to normal subjects, independently of vertebral fractures.

In several studies the QUALEFFO questionnaire demonstrated the ability to discriminate between patients with or without vertebral fractures [23]. The results of this study also show that QUALEFFO-41 is able to distinguish postmenopausal women with reduced BMD from normal subjects, independently of vertebral fractures. Other researchers have reported that among subjects without vertebral fractures, patients with osteoporosis have more severe functional impairment than patients with osteopenia [24]. Similar results have also been presented by Romagnoli et al. [28]: a low BMD is connected with a higher score for domains exploring physical function, general health perception and the total QUALEFFO score.

There was a good correlation between QUALEFFO-41 and WHOQOL-100, especially of the pain, ADL and mobility domains. Social function and jobs around the house were the domains with the lowest correlation between both scales. These differences indicate the importance of connected generic and specific questionnaires for evaluation of quality of life, especially in women with osteoporosis. These results are similar to the results of other studies using QUALEFFO and SF-36 [29].

Receiver operating characteristic curves analysis demonstrated a good discriminating capacity of individual domains and total QUALEFFO-41 score for patients with reduced BMD. The values of the area under the curve for each domain were from 0.58 (pain) to 0.68 (mobility). However, results of the original version show that QUALEFFO is 
successfully able to distinguish patients with vertebral fractures from hospital controls [18].

To sum up our analysis, we can make some important conclusions:

1) the score construction of the Polish version of QUALEFFO-41 is adequate. Scores of individual questions are better correlated with their own domain than with other domains, reflecting good discriminant validity. Scores of individual questions are better correlated with the domain score, reflecting good convergent validity.

2) Cronbach's $\alpha$ coefficient, reflecting the reliability of the Polish version of QUALEFFO-41 for all domains, is satisfactory. The results of test-retest reliability indicate good repeatability.

3) validity evaluated in several ways (analysis of the relationship between domain scores in QUALEFFO-41 and WHOQOL-100, analysis of means for three densitometry categories, analysis by comparing osteopenic and osteoporotic patients with or without vertebral deformities and ROC curve analysis) demonstrates the good property of this scale.

4) the Polish version of QUALEFFO-41 can be used among postmenopausal women with reduced BMD compared to normal subjects, independently of vertebral fractures. Carrying out in Poland the first assessment of psychometric properties of the Polish version of the QUALEFFO41 scale is a contribution to the development of knowledge in the assessment of quality of life. Satisfactory psychometric characteristics of the QUALEFFO-41 scale allow the use of this scale to evaluate the quality of life in postmenopausal women with reduced BMD by other Polish researchers.

5) the factor which determines the poor quality of life of postmenopausal women with reduced BMD is a functional state, expressed by reduced BMD, which limits physical activity and mobility, and produces postural deformities, pain and mood deterioration.

\section{References}

1. Melton LJ, Kallmes DF. Epidemiology of vertebral fractures: implications for vertebral augmentation Acad Radiol 2006; 13: $538-45$

2. Ismail AA, Cooper C, Felsenberg D, et al. Number and type of vertebral deformities: epidemiological characteristics and relation to back pain and height loss. Osteoporos Int 1999; 9: 206-13.

3. Hagsten B, Svensson O, Gardulf A. Health-related quality of life and self-reported ability concerning ADL and IADL after hip fracture. Acta Ortopedica 2006; 77: 114-9.

4. Bączyk G. Measuring quality of life in patients with osteoporosis - review of generic and disease specific quality of life measurement scales. Reumatologia 2009; 47: 300-6.
5. Bowling A. Measuring Health. A review of quality of life measurement scales. $2^{\text {nd }}$ ed. Open University Press, Buckingham-Philadelphia 1997.

6. Hunt SM, McEwen J, McKenna SP. Measuring health status: a new tool for clinicians and epidemiologists. J R Coll Gen Pract 1985; 35: 185-8.

7. Bergner M, Bobbitt RA, Carter WB, Gilson BS. The sickness impact profile: development and final revision of a health status measure. Med Care 1981; 19: 787-805.

8. Brazier JE, Harper R, Jones NMB. Validating the SF-36 health survey questionnaire: new outcome measures for primary care. BMJ 1992; 305: 160-4.

9. Kind P. The EuroQoL instrument: an index of healthrelated quality of life. In: Spilker B (ed.). Quality of life and pharmacoeconomics in clinical trials, $2^{\text {nd }}$ ed. LippincottRaven, Philadelphia 1996; 191-201.

10. Jaracz K, Kalfoss M, Górna K, Bączyk G. Quality of life in Polish respondents: psychometric properties of the Polish WHOQOL-Bref. Scand J Caring Sci 2006; 20: 251-60.

11. Cook DJ, Guyatt GH, Adachi JD, Epstein RS, Juniper EF. Development and validation of the Mini-Osteoporosis Quality of Life Questionnaire (OQLO) in osteoporotic women with back pain due vertebral fractures. Osteoporosis Quality of Life Study Group. Osteoporos Int 1999; 10: 207- 13.

12. Helmes E, Hodsman A, Lazowski D, et al. A questionnaire to evaluate disability in osteoporotic patients with vertebral compression fractures. Gerentol A Biol Sci Med Sci 1995; 50: M91-8.

13. Lydick E, Zimmerman SI, Yawn B, Love B. Development and validation of a discriminative Quality of life questionnaire for osteoporosis (the OPTQoL). J Bone Miner Res 1997; 12: 456-63.

14. Marquis R, Cialdella P, De La Loge C. Development and validation of a specific quality of life module for postmenopausal women with osteoporosis: the QUALIOST. Qual Life Res 2001; 10: 555-66.

15. Chandler JM, Martin AR, Girman C, Ross PD. Reliability of an osteoporosis targeted quality of life survey instrument for use in the community: OPTQoL. Osteoporos Int 1998; 8: 127-35.

16. Randell AG, Bhalerao N, Nguyen TV, Sambrook PN, Eisman JA, Silverman SL. Quality of life in osteoporosis: reliability, consistency, and validity of the Osteoporosis Assessment Questionnaire. J Rheumatol 1998; 25: 1171-9.

17. Silverman SL. The Osteoporosis Assessment Questionnaire (OPAQ): a reliable and valid disease-targeted measure of health-related quality of life in osteoporosis. Qual Life Res 2000; 9: 764-74.

18. Lips P, Cooper C, Agnusdei D, et al. Quality of life In patients with vertebral fractures: validation of the Quality of Life Questionnaire of the European Foundation for Osteoporosis (QUALEFFO). Working Party for Quality of Life of the European Foundation for Osteoporosis. Osteoporos Int 1999; 10: 150-60.

19. World Health Organization Study Group. Assessment of fracture risk and its application to screening for postmenopausal osteoporosis. In: WHO Technical Report Series, No. 843 WHO, Geneva 1994.

20. Genant HK, Wu CY, Yan Kuijk. Vertebral fracture assessment using a semiquantitative technique. J Bone Miner Res 1993; 8: 1137-48.

21. Nunnally JC. Psychometric Theory. McGraw-Hill, New York 1978.

22. Dequeker J, Ranstam J, Valsson J, et al. The Mediterranean Osteoporosis (MEDOS) Study Questionnaire. Clin Rheumatol 1991; 10: 54-72.

23. O'Neill TW; EVOS group. Reproducibility of the questionnaire on risk factors for osteoporosis in 
a multicentre prevalence survey: the European Vertebral Osteoporosis Study. Int J Epidemiol 1994; 23: 559-65.

24. Oleksik A, Lips P, Dawson A, et al. Health-Related Quality of Life (HRQOL) in postmenopausal women with low BMD with or without prevalent vertebral fractures. J Bone Miner Res 2000; 15: 1384-92.

25. Kanis JA, Minne HW, Meunier PJ. Quality of life and vertebral osteoporosis. Osteoporos Int 1992; 2: 161-3.

26. Martin AR, Sornay-Rendu E, Chandler JM. The impact of osteoporosis on quality-of-life: the OFELY cohort. Bone 2002; 31: 32-6.

27. Badia X, Diez-Perez A, Alvarez-Sanz C, et al. Measuring quality of life in women with vertebral fractures due to osteoporosis: a comparison of the OQLO and QUALEFFO. Qual Life Res 2001; 10: 307-17.

28. Romagnoli E, Carnevale V, Nofroni I, et al. Quality of life in ambulatory postmenopausal women: the impact of reduced bone mineral density and subclinical vertebral fractures. Osteopros Int 2004; 15: 975-80.

29. Ferreira NO, Arthuso M, Silva R, Pedro AO, Pinto Neto AM, Costa-Paiva L. Quality of life in women with postmenopausal osteoporosis: correlation between QUALEFFO 41 and SF-36. Maturitas 2009; 62: 85-9. 